\title{
XÁC ĐỊNH QUỸ ĐẠO VỆ TINH VIỄN THÁM PHÙ HỢP VỚI ĐIỀU KIỆN VIỆT NAM
}

\author{
CHU HẢI TÙNG, NGÔ DUY TÂN, \\ ĐẠNG TRƯỜNG GIANG, NGUYẼ̃N TH! THU HIÈN \\ Cục Viễn thám Quốc gia
}

\section{Tóm tắt:}

Xác định quỹ đạo của vệ tinh để đảm bảo khả năng hoạt động hiệu quả và ổn định của các vệ tinh viễn thám có ý nghĩa hết sức quan trọng. Bài báo đã trình bày các dạng quỹ đạo cơ bản của vệ tinh viễn thám cũng như các thông số chính, ưu nhược điểm của mỗi loại quỹ đạo. Trên cơ sở phân tích các đặc điểm của các quỹ đạo vệ tinh kết hợp với đặc điểm về hình thể lãnh thổ của Việt Nam nhóm tác giả đã xác định được dạng và các thông số cho quỹ đạo của vệ tinh viễn thám phù hợp với điều kiện của Việt Nam.

\section{Đặt vấn đề}

Ngày nay, dữ liệu ảnh chụp từ vệ tinh do các vệ tinh viễn thám cung cấp được ứng dụng rộng rãi trong nhiều lĩnh vực khác nhau như giám sát tài nguyên thiên nhiên, bảo vệ môi trường, phòng tránh thiên tai, ứng phó với biến đổi khí hậu cũng như phát triển kinh tế xã hội. Nhận thức rõ vai trò quan trọng và nhu cầu ngày càng tăng về các loại dữ liệu ảnh viễn thám, không chỉ có những nước phát triển với trình độ khoa học công nghệ tiên tiến mới sở hữu các vệ tinh viễn thám mà cả các nước đang phát triển, trong đó có Việt Nam, cũng quan tâm xây dựng các hệ thống viễn thám của riêng mình. Để đảm bảo cho mỗi hệ thống vệ tinh viễn thám hoạt động hiệu quả, đáp ứng được các mục tiêu đề ra thì bên cạnh các đặc tính kỹ thuật của hệ thống thiết bị trên vệ tinh một trong những yếu tố then chốt khác là vệ tinh phải có quỹ đạo phù hợp. Đặc biệt là, quỹ đạo của vệ tinh viễn thám phải được thiết kế sao cho thích hợp nhất với các điều kiện cụ thể của Việt Nam.

\section{Quỹ đạo của vệ tinh viễn thám}

\subsection{Các loại quỹ đạo vệ tînh}

Căn cứ theo độ cao so với mặt đất, quỹ đạo của các vệ tinh của trái đất, được chia làm 3 loại: quỹ đạo địa tĩnh (GEO Geostationary Earth Orbit), quỹ đạo trung bình (MEO - Mean Earth Orbit) và quỹ đạo thấp (LEO - Low Earth Orbit).

- Quỹ đạo địa tĩnh: thường ở độ cao 36.000 km so với bề mặt trái đất. Vệ tinh địa tĩnh bay cùng hướng và vận tốc quay của trái đất, theo đường tròn nằm trong mặt phẳng xích đạo. Do đó vệ tinh xuất hiện như một điểm cố định trên bầu trời, nói cách khác vệ tinh sẽ có vị trí không thay đổi so với một vị trí trên trái đất. Vệ tinh thông tin liên lạc và vệ tinh khí tượng thường được phóng lên quỹ đạo địa tĩnh.

- Quỹ đạo trung bình: là quỹ đạo có độ cao dưới $36.000 \mathrm{~km}$ và trên 3000 km. (Có tài liệu định nghĩa MEO là quỹ đạo có độ cao từ 5.000 km đến 15.000 km). Quỹ đạo này chủ yếu được dành cho vệ tinh thông tin liên lạc phủ vùng bắc cực và nam cực.

- Quỹ đạo thấp: là quỹ đạo nằm ở lớp trên của khí quyển trái đất có độ cao so với bề mặt trái đất từ $200-2000 \mathrm{~km}$, nhất là dưới 1000 km. Ở độ cao này, vệ tinh phải

Ngày nhận bài: 09/8/2017, ngày chuyển phản biện: 15/9/2017, ngày chấp nhận phản biện: 30/11/2017, ngày chấp nhận đăng: 04/12/2017 
bay nhanh để thắng được lực hút của trái đất. Phần lớn vệ tinh quan sát trái đất, tàu vũ trụ có người lái và trạm vũ trụ quốc tế ISS đều ở quỹ đạo thấp.

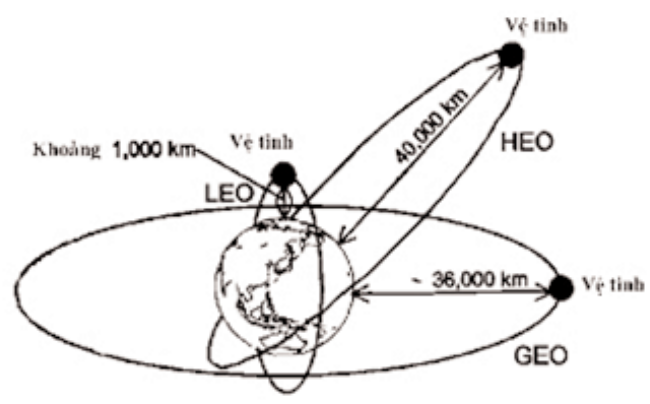

Hình 1: Phân loại quỹ đạo vệ tinh

Ngoài ra còn có một quỹ đạo đặc biệt là quỹ đạo eliptic nghiêng cao (HEO- Highly inclined Elliptical Orbit) có độ cao khoảng $40.000 \mathrm{~km}$ có độ nghiêng khoảng $64^{\circ}$ so với mặt phẳng xích đạo của trái đất.

\subsection{Quỹ đạo vệ tinh viễn thám}

Vệ tinh viễn thám thường được được bố trí trên quỹ đạo trái đất thấp (LEO), cho phép chụp ảnh với độ phân giải cao. Vệ tinh ở quỹ đạo thấp có vận tốc khoảng $7,9 \mathrm{~km} / \mathrm{s}$, cần khoảng 90-100 phút để bay một vòng quanh trái đất. Vệ tinh quỹ đạo thấp có nhiều loại như quỹ đạo cận cực, quỹ đạo đồng bộ mặt trời và quỹ đạo xích đạo, cận xích đạo.

Quỹ đao cưc - cân cưc (Polar - Near Polar Orbit) là quỹ đạo theo phương Bắc Nam và nghiêng một góc nhất định so với trục của trái đất. Mỗi ngày vệ tinh quỹ đạo cực (hoặc cận cực) bay quanh trái đất nhiều vòng, kết hợp với việc trái đất quay quanh trục sẽ cho phép vệ tinh thu nhận thông tin toàn bộ bề mặt trái đất sau một khoảng thời gian xác định.

Quỹ đao đồng bô măt trời (Sun Synchronous Orbit) là trường hợp đặc biệt của quỹ đạo cực. Vệ tinh quỹ đạo đồng bộ mặt trời chuyển động sao cho mặt phẳng quỹ đạo vệ tinh luôn luôn có cùng một góc so với trục Trái đất - Mặt trời. Vì vậy, vệ tinh luôn bay qua một điểm nhất định trên trái đất vào một thời gian không đổi (theo giờ địa phương).

Quỹ đạo xích đạo và cân xích đạo: Vệ tinh viễn thám có quỹ đạo thấp xích đạo/cận xích đạo để tăng tần suất vệ tinh bay qua các nước có lãnh thổ chạy dọc theo xích đạo.

\subsection{Các khái niệm, thông số kỹ thuật của quỹ đạo vệ tinh}

1.3.1. Các khái niệm mô tả quỹ đạo vệ tinh

Quỹ đạo của vệ tinh trái đất có thể tròn (hoặc gần tròn) hoặc có dạng elip.

Các thông số mô tả quỹ đạo vệ tinh bao gồm:

- Chu kỳ quỹ đạo: Là thời gian để vệ tinh bay được trọn vẹn một vòng quanh trái đất trên quỹ đạo của nó. Chu kỳ quỹ đạo khác nhau đối với các vệ tinh và quỹ đạo khác nhau, ví dụ với vệ tinh quỹ đạo cực là 90 100 phút thì vệ tinh quỹ đạo địa tĩnh là 24 giờ.

- Độ cao: độ cao của vệ tinh là khoảng cách giữa vệ tinh và bề mặt ngay bên dưới nó. Tùy thuộc vào mục tiêu thiết kế của vệ tinh, quỹ đạo có thể đặt ở độ cao thấp (160 $-2000 \mathrm{~km}$ ), trung bình (>3000 km), và cao $(36000 \mathrm{~km})$.

- Viễn điểm (apogee): là điểm nằm trên quỹ đạo vệ tinh ở xa nhất so với tâm Trái đất.

- Cận điểm (perigee): là điểm nằm trên quỹ đạo vệ tinh ở gần nhất so với tâm Trái đất.

- Góc nghiêng (inclination): là góc giữa mặt phẳng xích đạo và mặt phẳng quỹ đạo. Góc nghiêng được tính ngược chiều kim đồng hồ bắt đầu từ xích đạo. Góc nghiêng của các vệ tinh viễn thám thường xấp xỉ 99 ${ }^{\circ}$, 
góc nghiêng của các vệ tinh có quỹ đạo gần với mặt phẳng xích đạo là xấp xỉ 180 .

- Nadir, ground track and zenith: Nadir (đế) là giao điểm giữa bề mặt trái đất với đường nối vệ tinh với tâm trái đất (hay đường từ vệ tinh thẳng góc với bề mặt trái đất). Nadir là điểm trên bề mặt đất có khoảng cách ngắn nhất tới vệ tinh.

Bất kỳ điểm nào đối diện với điểm Nadir và ở phía trên của vệ tinh được gọi là thiên đỉnh. Đường tròn trên bề mặt trái đất tạo bởi các điểm nadir khi vệ tinh chuyển động xung quanh trái đất được gọi là vết của vệ tinh (ground track hay footprint). Nói cách khác, vết của vệ tinh là đường tạo bởi hình chiếu của quỹ đạo vệ tinh trên bề mặt trái đất.

- Độ rộng dải chụp: Độ rộng dải chụp của vệ tinh là độ rộng của dải trên bề mặt trái đất được chụp vởi hệ thống chụp ảnh trên vệ tinh trong một pass đơn lẻ.

- Chu kỳ lặp lại của vệ tinh quỹ đạo trái đất thấp là khoảng thời gian để vệ tinh quay lại đường đi trước đó của nó, khi điểm nadir của vệ tinh trùng với một điểm trên trái đất lần thứ hai. Ví dụ, chu kỳ lặp lại của các vệ tinh SPOT là 26 ngày, vệ tinh Landsat 8 là 16 ngày.

- Thời gian chụp lặp lại hay tần suất chụp lặp lại là khoảng thời gian mà bộ cảm biến trên vệ tinh có thể chụp ảnh quay lại cùng một khu vực trên mặt đất lần thứ hai. Đối với các hệ thống viễn thám có thể nghiêng xoay để chụp ảnh lệch về hai phía so với quỹ đạo của vệ tinh thì thời gian chụp lặp lại có thể ngắn hơn chu kỳ lặp lại của vệ tinh. Ví dụ, hệ thống SPOT 6/7 có thể chụp lặp lại một khu vực trên bề mặt đất trong 3 ngày.

\subsubsection{Các thông số quỹ đạo vệ tinh của Kepler}

Thông số quỹ đạo là các thông số dùng để xác định quỹ đạo vệ tinh. Trong thiên văn học, thường dùng một bộ gồm 6 thông số là thông số quỹ đạo Kepler (đặt theo tên của nhà thiên văn học Johannes Kepler). Trên thực tế, quỹ đạo thực của vệ tinh luôn thay đổi theo thời gian do ảnh hưởng của nhiều yếu tố khác nhau như nhiễu của lực hấp dẫn từ các đối tượng khác (Mặt Trăng, Mặt Trời..), ma sát với khí quyển, bức xạ Mặt Trời.... Do đó thông số quỹ đạo Kepler chỉ là ước lượng tương đối tại một thời điểm nhất định.

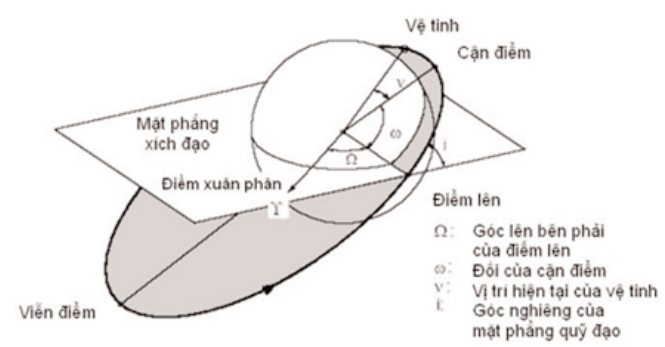

Hình 3: Bộ 6 thông số quỹ đạo Kepler

Một quỹ đạo sẽ bao gồm hai bộ thông số Kepler phụ thuộc vào vật thể nào được chọn làm mốc. Vật thể làm mốc sẽ được gọi là chính, vật còn lại sẽ là phụ. Vật chính không nhất thiết phải có khối lượng lớn hơn vật phụ, ngay cả trong trường hợp hai vật thể cùng khối lượng, thông số quỹ đạo chỉ phụ thuộc vào việc chọn vật nào làm vật chính.

Bán trục lớn ( $a-$ semi major axis): bằng một nửa tổng độ lớn của viễn điểm và cận điểm. Đối với quỹ đạo tròn, bán trục lớn chính bằng khoảng cách giữa tâm của hai vật thể.

Độ lệch tâm (e- eccentricity): quyết định hình dạng quỹ đạo, e càng lớn thì độ dẹt quỹ đạo càng tăng $(e=0$ quỹ đạo là hình tròn).

Góc nghiêng của quỹ đạo (i-inclination of an orbit): là góc nghiêng giữa xích đạo và mặt phẳng quỹ đạo (chiều dương theo hướng bắc).

Kinh độ của điểm lên (longitude of the ascending node): góc giữa điểm lên và điểm Xuân phân . 
Đối của cận điểm (argument of periapsis): thông số xác định hướng của elip trong mặt phẳng quỹ đạo, là góc giữa điểm lên so với cận điểm (điểm trên quỹ đạo mà tại đó khoảng cách vật phụ với vật chính là gần nhất).

Vị trí hiện tại của vệ tinh (true anomaly): là góc tính từ cận điểm đến vị trí của vệ tinh. Giá trị của vị trí hiện tại được tính theo hướng chuyển động của vệ tinh $\left(0^{\circ}-360^{\circ}\right)$.

\section{Xác định quỹ đạo cho vệ tinh viễn thám phù hợp với Việt Nam}

\subsection{Quỹ đạo cận cực - đồng bộ mặt trời và quỹ đạo cận xích đạo}

Phần lớn các vệ tinh viễn thám quỹ đạo cận cực cũng là vệ tinh có quỹ đạo đồng bộ mặt trời. Quỹ đạo này cho phép vệ tinh chụp ảnh mỗi khu vực trên trái đất tại cùng một giờ địa phương. Đặc điểm này đảm bảo duy trì điều kiện chiếu sáng ổn định, nhất quán khi chụp ảnh cho một khu vực nào đó theo mùa trong nhiều năm. Đây là yếu tố quan trọng để giám sát sự biến động trên bề mặt theo chuỗi thời gian mà không cần hiệu chỉnh ảnh hưởng do điều kiện chiếu sáng khác nhau. Những dữ liệu ảnh thu nhận vào các ngày khác nhau nhưng cùng mùa sẽ có điều kiện chiếu sang gần giống nhau, nên thuận lợi cho việc so sánh, phân tích.

Quỹ đạo thấp cận xích đạo cũng được lựa chọn trong một số trường hợp. Quỹ đạo này có góc nghiêng so với xích đạo thấp, dẫn đến tăng tần suất quay lại của vệ tinh. Ví dụ như Malayxia đã thiết kế vệ tinh RazakSAT có quỹ đạo thấp, cận xích đạo để tăng khả năng chụp lặp lại của vệ tinh trên lãnh thổ nước mình. Vệ tinh viễn thám của Brazin SSR cũng được thiết kế có quỹ đạo xích đạo để thuận tiện cho việc giám sát rừng Amazon nằm dọc theo xích đạo.

Ưu điểm chính của quỹ đạo cận xích đạo là có thể tăng được tần suất chụp ảnh, thời gian chụp lặp trung bình khoảng 12-16h, tùy theo quỹ đạo thiết kế của mỗi vệ tinh. Kết hợp với khả năng xoay, nghiêng của bộ cảm biến và vệ tinh có thể chụp ảnh một đối tượng cụ thể trên bề mặt với tần suất lên đến $4-6$ lần/ngày. Vệ tinh viễn thám quỹ đạo cận xích đạo rất thích hợp với những nước có lãnh thổ ở khu vực xích đạo và trải dài theo hướng Đông - Tây, như Indonesia, Malaysia, Brazin.

Nhược điểm chính của các vệ tinh bay theo quỹ đạo xích đạo/cận xích đạo là:

Ảnh chụp tại các thời điểm khác nhau trong ngày với điều kiện chiếu sáng khác nhau dẫn đến khó khăn trong việc giải đoán, phân tích, so sánh các đối tượng trên ảnh.

Chỉ có thể quan sát và chụp ảnh ở các khu vực nằm xung quanh vành đai xích đạo.

Vệ tinh phải bay qua vành đai Van-Allen ở phía Nam Đại Tây Dương nơi có mật độ các hạt vật chất ảnh hưởng lớn đến hoạt động của các thiết bị trên vệ tinh dẫn đến giảm tuổi thọ của vệ tinh.

Do những đặc điểm nêu trên, đa số các vệ tinh viễn thám được ưu tiên thiết kế với quỹ cận cực và đồng bộ mặt trời nhằm đảm bảo chụp ảnh độ phân giải không gian cao, ổn định, phủ trùm được phần lớn bề mặt trái đất và điều kiện chiếu sáng tương đối giống nhau.

\subsection{Xác định dạng quỹ đạo phù hợp cho Việt Nam}

Quỹ đạo cận xích đạo phù hợp cho các nước có lãnh thổ trải dài dọc theo xích đạo. Tuy nhiên, Việt Nam có lãnh thổ tương đối nhỏ, hẹp trải dài từ Bắc xuống $\mathrm{Nam}$, chỗ rộng nhất cũng chỉ lên đến $600 \mathrm{~km}$ trong khi nhiều vùng rất hẹp. Nếu sử dụng quỹ đạo cận xích đạo thì mặc dù có thể tăng số lần vệ tinh bay qua lãnh thổ lên nhiều lần trong ngày, nhưng số lượng ảnh chụp được trên mỗi dải bay là rất ít, dẫn đến hiệu quả chụp ảnh kém.Mặt khác, các ảnh do vệ tinh quỹ đạo cận xích đạo chụp được cũng rất khó 
xử lý, khai thác do điều kiện chiếu sáng khác nhau và tính chất hình học đặc biệt của chúng. Một nhược điểm lớn nữa của vệ tinh quỹ đạo cận xích đạo là dễ hỏng hóc, tuổi thọ không cao.

Do đó, có thể nói rằng vệ tinh viễn thám quỹ đạo cận cực - đồng bộ mặt trời sẽ phù hợp với điều kiện của Việt Nam hơn so với quỹ đạo cận xích đạo.

\subsection{Lựa chọn các thông số quỹ đạo} của vệ tinh viễn thám phù hợp cho Việt Nam

Khi thiết kế quỹ đạo cho vệ tinh viễn thám, đặc biệt là các vệ tinh quỹ đạo cận cực-đồng bộ mặt trời, các thông số được quan tâm nhiều nhất là số quỹ đạo vệ tinh thực hiện được trong một ngày, tổng số quỹ đạo vệ tinh thực hiện được trong một chu kỳ lặp lại của vệ tinh. Từ các thông số này có thể xác định được độ cao, các bán trục, góc nghiêng của quỹ đạo. Kết hợp với đặc điểm, năng lực của bộ cảm biến sẽ xác định được tần suất chụp lặp...

Để biểu diễn các đặc tính của chu kỳ lặp lại của một quỹ đạo ta sử dụng 3 số nguyên $\mathrm{n}, \mathrm{p}, \mathrm{q}$. Số quỹ đạo trong ngày được biểu diễn bằng công thức:

$$
M=n+p / q
$$

Trong đó: - M là số quỹ đạo vệ tinh thực hiện được trong 1 ngày;

- $\mathrm{n}$ thể hiện phần nguyên của số quỹ đạo thực hiện được trong 1 ngày;

- q chu kỳ lặp lại của quỹ đạo (tính theo ngày);

- p/q thể hiện phần quỹ đạo thực hiện được sau khi trừ đi phần nguyên

Như vậy trong q ngày vệ tinh sẽ thực hiện được $n . q+p$ quỹ đạo. Vệ tinh sẽ bay qua một điểm cố định trên Trái Đất trong mỗi q ngày do đó có thể gọi q là vòng lặp. Số vệt bay trong một chu kỳ bay sẽ tạo trên bề mặt trái đất một lưới vệt đặc trưng cho mỗi vệ tinh.

Các vệ tinh quỹ đạo thấp cận cực bay quanh trái đất một vòng mất khoảng 90', do đó mỗi ngày sẽ thực hiện được khoảng 1416 quỹ đạo tương ứng với $m=14,15$.

Vòng lặp phụ: là khoảng cách gần nhất giữa 2 vệt bay nằm cạnh nhau trong một chu kỳ quỹ đạo. Vòng lặp phụ được tính theo công thức sau:

$$
\mathrm{Si}=\text { chu vi trái đất tại xích đạo/(n.q) }
$$

Vệ tinh chỉ có khả năng phủ trùm toàn cầu nếu trường nhìn của nó (phạm vi quan sát) lớn hơn kích thước của vòng lặp phụ.

Bảng 1: Các thông số quỹ đạo của một số vệ tinh

\begin{tabular}{|c|c|c|c|c|c|}
\hline Vệ tinh & MOS-1,-1b & JERS-1 & ADEOS & ADEOS-2 & ALOS \\
\hline Số quỹ đạo trong 1 ngày & $14+1 / 17$ & $15+1 / 44$ & $14+11 / 41$ & $14+1 / 4$ & $14+27 / 46$ \\
\hline Độ cao quỹ đạo (km) & 908.79 & 568.04 & 796.75 & 802.92 & 691.65 \\
\hline Góc nghiêng quỹ đạo (độ) & 99.07 & 97.67 & 98.50 & 98.62 & 98.16 \\
\hline Tổng số vòng lặp lại & 237 & 659 & 585 & 57 & 671 \\
\hline Chu kỳ lặp lại (repeat cycle) & $(17)$ & $(44)$ & 4 & $(4)$ & 46 \\
\hline Khoảng chồng (\%) & 18 & 23 & 17 & $(120)$ & 17 \\
\hline $\begin{array}{c}\text { Độ rộng dải quét của sensor } \\
\text { chính }\end{array}$ & $\begin{array}{c}\text { MESSR : 100 } \\
\mathrm{km} \times 2\end{array}$ & $\begin{array}{c}\text { SAR,OPS : } 75 \\
\mathrm{~km}\end{array}$ & AVNIR : $80 \mathrm{~km}$ & GLI : 1600km & PRISM : 70km \\
\hline
\end{tabular}


Để xây dựng một quỹ đạo thực hiện nhiệm vụ cho một vệ tinh trước hết ta phải xây dựng và lựa chọn được bộ số $n, p, q$ thích hợp.

Với các giá trị của $\mathrm{n}, \mathrm{p}$, q khác nhau sẽ cho ta các quỹ đạo khác nhau vì vậy xác định được các giá trị $n, p$, q phù hợp với tiêu chí quỹ đạo đặt ra là điều kiện tiên quyết để xây dựng một quỹ đạo thực hiện nhiệm vụ cho vệ tinh. Sau khi lựa chọn được các số $\mathrm{n}, \mathrm{p}, \mathrm{q}$ ta sẽ tính được các tham số chính của quỹ đạo, bao gồm chu kỳ, độ cao của quỹ đạo, bán trục lớn, vận tốc của vệ tinh, góc nghiêng quỹ đạo và góc nghiêng tối thiểu để vệ tinh có thể phủ trùm hoàn toàn bề mặt trái đất trong một khoảng thời gian cho trước.

Mục tiêu cơ bản của các vệ tinh quan sát trái đất là đáp ứng nhu cầu về dữ liệu ảnh viễn thám của người sử dụng. Các yêu cầu đó bao gồm: tần suất chụp ảnh lặp lại, diện tích phủ trùm (độ rộng dải chụp), độ phân giải không gian, số lượng kênh phổ, độ phân giải radiometric... Để đạt được các thông số tối ưu cho vệ tinh viễn thám, đáp ứng một cách hiệu quả các yêu cầu đề ra cần kết hợp cả thiết kế, xác định các thông số quỹ đạo với các đặc điểm tính năng kỹ thuật của bộ cảm biến cũng như các phân hệ thiết bị khác trên vệ tinh.

Tuy nhiên, bài báo này chỉ phân tích lựa chọn quỹ đạo phù hợp với Việt Nam, trong đó giả định là vệ tinh quang học có khả năng xoay ống kính lên đến $\pm 30^{\circ}$. Với khả năng xoay ống kính như vậy sẽ cho phép vệ tinh có khả năng tiếp cận và chụp ảnh bất kỳ vị trí nào trong một dải rộng tới $500-900$ km (tương ứng với độ cao quỹ đạo từ 500 $800 \mathrm{~km}$ ) xung quanh vết của vệ tinh chiếu trên mặt đất.

+ Đáp ứng nhu cầu về dữ liệu ảnh viễn thám độ phân giải cao

Phần lớn các ứng dụng dữ liệu viễn thám như đo đạc bản đồ, môi trường, giám sát tài nguyên rừng, đất đai, biển, đường bờ, địa chất đều có thể được thỏa mãn nếu vệ tinh có khả năng tiếp cận toàn bộ lãnh thổ trong vòng 3 ngày và chu kỳ lặp lại dưới 1 tháng. Riêng đối với các yêu cầu khẩn cấp phục vụ quốc phòng an ninh, hoặc phòng tránh thiên tai khả năng tiếp cận và chụp lặp lại trong 12 ngày. Do đó, cần xác định rõ mục tiêu ứng dụng của vệ tinh viễn thám trước khi thiết kế quỹ đạo của chúng.

\section{+ Thời điểm vệ tinh bay qua}

Do Việt Nam nằm ở vùng nhiệt đới gió mùa, luôn có nhiều mây và các đám mây thường hình thành vào nửa sau của mối ngày. Vì vậy, thời gian chụp ảnh hay thời điểm vệ tinh bay qua các khu vực trên lãnh thổ Việt Nam nên nằm trong buổi sáng, tốt nhất là từ $9 \mathrm{~h}-11 \mathrm{~h} 30$. Đây cũng là khoảng thời gian có bức xạ mặt trời mạnh nhất và thuận lợi cho chụp ảnh.

$$
\text { + Phù hợp với đặc điểm lãnh thổ Việt }
$$
Nam

Quỹ đạo của vệ tinh viễn thám cần thiết kế phù hợp với vị trí địa lý của Việt Nam sao cho có thể đạt hiệu quả chụp ảnh cao nhất.

Vị trí địa lý của Việt Nam

+ Vĩ độ: Việt Nam nằm trong khoảng từ 2323'Bắc (Lũng Cú - Đồng Văn - Hà Giang)

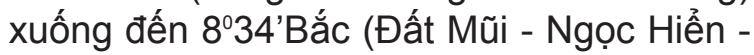
Cà Mau).

+ Kinh độ: Từ 102010'Đông (Xín Thầu Mường Nhé - Điện Biên) đến 109²4'Đông (Vạn Thạch - Vạn Ninh - Khánh Hoà).

Có thể thấy lãnh thổ Việt Nam tương đối hẹp (khoảng cách từ Tây sang Đông lớn nhất khoảng $600 \mathrm{~km}$ ) kéo dài từ Bắc xuống Nam khoảng $2000 \mathrm{~km}$. Nếu ta xác định một hình chữ nhật dài 2000 km, rộng 600 km bao phủ trọn vẹn lãnh thổ Việt Nam (chủ yếu là phần đất liền) thì cần thiết kế quỹ đạo của vệ tinh sao cho vết của vệ tinh trên bề mặt trái đất (hướng quỹ đạo) phải song 
song với trục dọc của hình chữ nhật nói trên. Nói cách khác, góc nghiêng của quỹ đạo vệ tinh phải xấp xỉ với góc tạo bởi trục dọc của hình chữ nhật với xích đạo ( 980$\left.99^{\circ}\right)$. Với góc nghiêng quỹ đạo như trên sẽ cho phép vệ tinh chụp được nhiều nhất những dải ảnh dài dọc theo lãnh thổ Việt Nam mà ít phải thay đổi tư thế của vệ tinh và thiết bị chụp ảnh. (Xem hình 5)

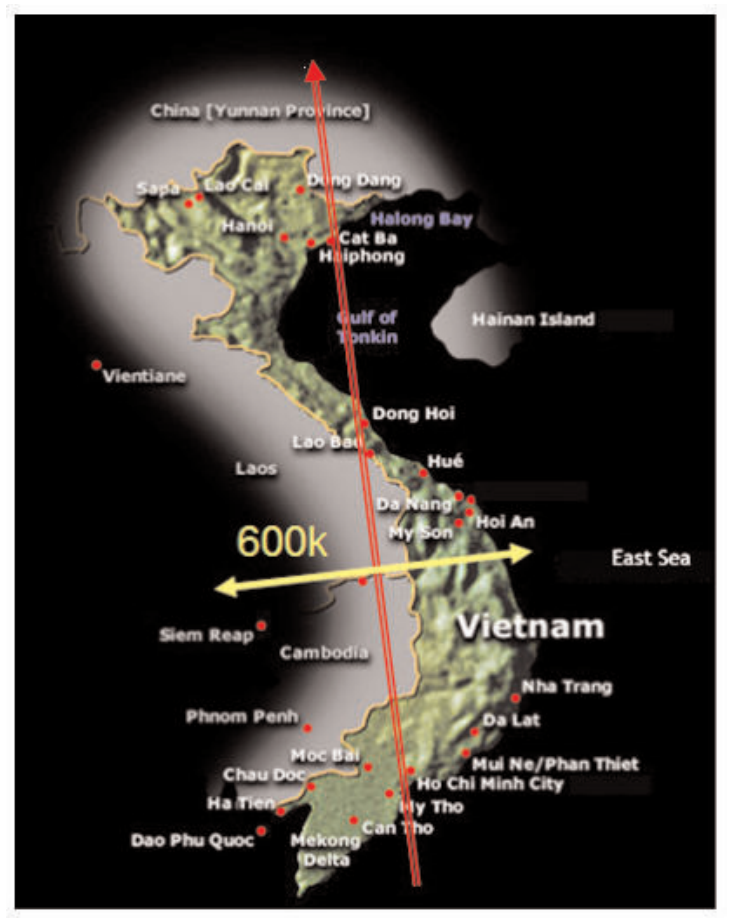

Hình 5: Xác định hướng quỹ đạo vệ tinh

Vậy quỹ đạo vệ tinh viễn thám phù hợp với điều kiện Việt Nam sẽ là:

- Quỹ đạo đồng bộ mặt trời.

- Độ cao quỹ đạo 500 - 800 km

- Quan sát (tiếp cận) được toàn bộ vùng lãnh thổ Việt Nam trong thời gian ngắn nhất (1-2 ngày cho các yêu cầu khẩn cấp, từ 3 ngày trở lên cho các yêu cầu thông thường);

- Có chu kỳ lặp lại dưới 1 tháng;

- Góc nghiêng so với mặt phẳng xích đạo $\sim 98^{\circ}-99^{\circ}$
- Giờ địa phương khi vệ tinh bay qua vào buổi sáng $(9 \mathrm{~h}-11 \mathrm{~h} 30)$;

Một số bộ tham số $m, n, p$ thường dùng có khả năng đáp ứng được yêu cầu trên là: $14+5 / 26,14+15 / 26,14+19 / 29$.

Một ví dụ tiêu biểu là quỹ đạo của vệ tinh viễn thám VNREDSat-1của Việt Nam, có các thông số $m, n, p$ tương ứng là: $14+$ 18/29. Kết hợp với các điều kiện nêu trên và các kết quả tính toán sẽ xác định được các thông số còn lại của quỹ đạo như trong bảng 2 .

Bảng 2: Các thông số quỹ đạo của vệ tinh VNREDSat-1 sau khi đã hiệu chỉnh

\begin{tabular}{|c|c|}
\hline Thời điểm & 2013/05/14 04:00 \\
\hline a $(\mathrm{km})$ & 7059.045 \\
\hline Độ cao khi qua xích đạo $(\mathrm{km})$ & 681.045 \\
\hline Độ lệch tâm & 0.001193 \\
\hline i (góc nghiêng quỹ đạo) & 98.13313 \\
\hline RAAN (độ) & 212.57169 \\
\hline w (độ) & 90.26950 \\
\hline M (độ) & 224.7033 \\
\hline Chu kỳ (giây) & 5909.4 \\
\hline
\end{tabular}

Với quỹ đạo như vậy trong mỗi ngày vệ tinh bay được $14+18 / 29$ vòng xung quanh trái đất, chu kỳ lặp lại là 29 ngày. Quỹ đạo được chọn cho phép vệ tinh có thể tiếp cận và chụp mọi khu vực trên thế giới, đặc biệt là phần lãnh thổ Việt Nam, với thời gian kể từ khi nhận yêu cầu không quá 3 ngày với góc xoay của vệ tinh so với hướng vuông góc mặt đất tối đa 35 độ và không quá 8 ngày với góc xoay tối đa 10 độ.

\section{Kết luận}

Thiết kế quỹ đạo cho vệ tinh, bao gồm cả các vệ tinh viễn thám, có vai trò rất quan trọng để đảm bảo sự hoạt động hiệu quả và ôn định của vệ tinh. Tuy nhiên, đây là một 
công việc hết sức phức tạp cần phải phân tích đánh giá, mô hình hóa, tính toán rất nhiều các thông số khác nhau cũng như các yêu cầu khác nhau tùy thuộc vào điều kiện của từng nước hay từng dự án phát triển vệ tinh viễn thám. Việc thiết kế quỹ đạo của vệ tinh viễn thám trước tiên cần phải hướng tới đáp ứng nhu cầu của người sử dụng, chi phí hợp lý-hiệu quả, năng lực chụp ảnh cao nhất (trong điều kiện cho phép), mức độ an toàn cao, ít rủi ro. Trên cơ sở nghiên cứu các đặc điểm, tính chất của các dạng quỹ đạo, các thông số tương ứng cũng như nhu cầu về dữ liệu và điều kiện về hình thể của lãnh thổ Việt Nam, nhóm nghiên cứu đã xác định được quỹ đạo tương đối phù hợp cho các vệ tinh viễn thám cỡ nhỏ của Việt Nam. Cụ thể là: Quỹ đạo thấp đồng bộ mặt trời; độ cao 500 - 800 km; góc nghiêng so với mặt phẳng quỹ đạo $98-99^{\circ}$, giờ địa phương khi qua Việt Nam trong khoảng 9 giờ sáng tới 11 giờ 30 sáng đảm bảo điều kiện chiếu sáng Mặt trời là tối ưu; mỗi ngày vệ tinh thực hiện được 14 -15 vòng xung quanh trái đất, chu kỳ lặp lại khoảng 26 -29 ngày. 0

\section{Tài liệu tham khảo}

[1]. Trần Mạnh Tuấn và nhiều tác giả khác, Công nghệ vệ tinh, Nhà xuất bản Khoa học kỹ thuật, 2007.

[2]. Wilbur L. Pitchrad, Henri
G.Suyderhound, Robert A. Nelson, Satellite Communication System Engineering, PTR Prentice Hall Press. Alex da Silva Curiel, Orbital Motion, 2000.

[3]. Marcel J. Sidi, Spacecraft dynamics and control, Cambrigde University Press, 1997.

[4]. Michel Capderou, Satellites Orbits and Missions, Springer-Verlag France 2005

Klaus Schilling ,Mission analyses for Low-Earth-observation missions with Spacecraft formations, Julius-MaximiliansUniversity

[5]. ASTRIUM company, Mission analysis document of VNREDSAT-1 project

[6]. Wikipedia Orbital elements. http://en.wikipedia.org/wiki/Orbital_elements

[7]. Larson, W. J. and Wertz, J. R. , Space Mission Analysis and Design ( $3^{\text {rd }}$ edtion) Kluwer Academic Publishers, Dordrecht, 1999

[8]. Fortescue. P. W. and Stark, J. P. W. (ed.), Spacecraft Systems Engineering. Wiley. New York, 1991.

[9]. Vallado, D.A., Fundamentals of Astrodynamics and Applications, McGrawHill 1997.O

\section{Summary}

\section{Determining satellite orbits suitable for Vietnam conditions}

Chu Hai Tung, Ngo Duy Tan, Dang Truong Giang, Nguyen Thi Thu Hien

\section{Department of National Remote Sensing}

Determining orbits is crucial for efficient and stable operation of remote sensing satellites. This paper introduces basic types of orbits for remote sensing satellites, their main parameters as well as advantages and limitations for each type of orbits. Based on analysis of orbital properties in combination with shape of Vietnamese territory, the authors have defined orbital types and parameters for remote sensing satellites which are appropriate for conditions of Vietnam. O 